\title{
Identifiable Class
}

National Cancer Institute

\section{Source}

National Cancer Institute. Identifiable Class. NCI Thesaurus. Code C44469.

A class that has an unambiguous reference within the scope. It also has a potentially ambiguous name. 